\title{
Dispersion optimised impairment constraint based routing and wavelength assignment algorithms for all-optical networks
}

\section{Citation for published version (APA):}

Zulkifli, N., Okonkwo, C. M., \& Guild, K. M. (2006). Dispersion optimised impairment constraint based routing and wavelength assignment algorithms for all-optical networks. In Proceedings of the 2006 International Conference on Transparent Optical Networks, June 2006, Nottingham (Vol. 3, pp. 177-180). Institute of Electrical and Electronics Engineers. https://doi.org/10.1109/ICTON.2006.248430

DOI:

10.1109/ICTON.2006.248430

Document status and date:

Published: 01/01/2006

\section{Document Version:}

Publisher's PDF, also known as Version of Record (includes final page, issue and volume numbers)

\section{Please check the document version of this publication:}

- A submitted manuscript is the version of the article upon submission and before peer-review. There can be important differences between the submitted version and the official published version of record. People interested in the research are advised to contact the author for the final version of the publication, or visit the $\mathrm{DOI}$ to the publisher's website.

- The final author version and the galley proof are versions of the publication after peer review.

- The final published version features the final layout of the paper including the volume, issue and page numbers.

Link to publication

\section{General rights}

Copyright and moral rights for the publications made accessible in the public portal are retained by the authors and/or other copyright owners and it is a condition of accessing publications that users recognise and abide by the legal requirements associated with these rights.

- Users may download and print one copy of any publication from the public portal for the purpose of private study or research.

- You may not further distribute the material or use it for any profit-making activity or commercial gain

- You may freely distribute the URL identifying the publication in the public portal.

If the publication is distributed under the terms of Article 25fa of the Dutch Copyright Act, indicated by the "Taverne" license above, please follow below link for the End User Agreement:

www.tue.nl/taverne

Take down policy

If you believe that this document breaches copyright please contact us at:

openaccess@tue.nl

providing details and we will investigate your claim. 


\title{
Dispersion Optimised Impairment Constraint Based Routing and Wavelength Assignment Algorithms for All-Optical Networks
}

\author{
Nadia Zulkifli, Chigo Okonkwo, Student Member, IEEE and Ken Guild, Member, IEEE \\ Department of Electronic System Engineering, University of Essex, CO43SQ, United Kingdom \\ E-mail:\{nzulki,cmokon,kguild\}@essex.ac.uk
}

\begin{abstract}
Current methods in the area of Impairment Constraint Based Routing Algorithms (ICBRA) lack the capabilities to support information regarding dispersion management. The inclination towards higher bit-rates and heterogeneous optical networks in the future challenges the popular assumption that chromatic dispersion (CD) is adequately compensated on a per-link basis. Recognising the importance of dispersion management, this paper proposes algorithms which apply metrics that contain dispersion information to both the routing and wavelength assignment sub-problems. To the best of our knowledge, this is the first attempt to include dispersion information within the wavelength assignment sub-problem. The newly proposed algorithm is named Dispersion Optimised Impairment Constraint-based RWA (DOIC). The performance is compared to existing routing and wavelength techniques under two scenarios: $40 \mathrm{~Gb} / \mathrm{s}$ and mixed $10 \mathrm{~Gb} / \mathrm{s} / 40 \mathrm{~Gb} / \mathrm{s}$ services. Two physical impairments under investigation are Chromatic Dispersion (CD) and Optical Signal to Noise Ratio (OSNR).
\end{abstract}

Keywords: ICBRA, RWA, chromatic dispersion, OSNR, signal quality, transmission impairment.

\section{INTRODUCTION}

Signal quality in transparent WDM networks become subject to a variety of linear and non-linear impairments in the cascade of transmission lines and optical switching devices [1]. The latter is much more complicated because of the strong dependencies on optical power intensity and the presence of other channels. The majority of Impairment Constraint Based Routing Algorithm (ICBRA) reported in literature focus on OSNR degradation and PMD [2, 3]. Chromatic dispersion (CD) is always assumed to be adequately compensated on a per-link basis and although the work in [4] considered $\mathrm{CD}$, the dispersion slope was not considered and all wavelengths were assumed to accumulate the same amount of dispersion per link. However, for high bit-rate systems $(\geq 10 \mathrm{~Gb} / \mathrm{s}$ ), dispersion slope becomes a significant factor since tolerance to $\mathrm{CD}$ is reduced by the square of bitrate [5]. Therefore, inclusion of CD into a RWA, which incorporates dispersion slope, is seen as a key factor for an efficient utilisation of network resources in a future transparent WDM network.

The newly proposed algorithm is named Dispersion Optimised Impairment Constraint-based RWA (DOIC) and involves modifications to both the routing and wavelength sub-problems. Constraints related to CD and OSNR are first introduced at the routing level. Once a path is chosen, DOIC assigns a wavelength that is within the acceptable dispersion range (for a given bit-rate) and that will also contribute to lower blocking probability for future connections. Further details on DOIC and two other benchmark algorithms (Conventional DisTancebased $(C D T)$ and Modified Future Cost $(M F C)$ ) will be provided in Section 3. All algorithms are run on a transmission line model which employs the concept of optimised dispersion management [6]. In addition to single bit-rate systems, we are also interested to see how the proposed ICBRA and wavelength assignment algorithms perform in a mixed bit-rate environment. Providing bit-rate differentiated services that are defined by physical layer impairments is an attractive option for future optical networks [2]. In order to observe the benefits of the algorithms, very low Polarization Mode Dispersion (PMD) values have been assumed $(<0.05 \mathrm{ps} / \sqrt{\mathrm{km}})$. Since PMD is a non-wavelength sensitive effect, it is expected that the blocking probability will be increased for long distance $40 \mathrm{~Gb} / \mathrm{s}$ connection requests in network scenarios with more realistic PMD values.

The remainder of this report is organised as follows. In section 2, physical impairments related to our work are explained. Section 3 explains the proposed dispersion optimised ICBRA and its implementation. Simulation scenarios and results are presented in Section 4 and finally some concluding remarks are outlined in Section 5.

\section{PHYSICAL IMPAIRMENTS}

\subsection{Chromatic dispersion (CD) and dispersion management}

The rule of thumb for an effective dispersion management is to keep local dispersion high but total end-to-end accumulated dispersion low. High local dispersion is required so that large walk-off between channels and phase-mismatching conditions can be created. As a result, the destructive effects from inter channel non-linear interactions (particularly XPM and FWM) can be mitigated. Currently, SMF + DCF is the potential candidate for this purpose as both have high local dispersion. It is more economical as well since this combination has 
been widely installed, thus easing the requirement for new fibre upgrades. Apart from that, optimum dispersion management also demands under-compensation (keeping some Residual Dispersion (RD)) to lessen non-linear interactions at the beginning of every span and accumulation of non-linear effects. Aforementioned dispersion management techniques were implemented by N. Hanik, et al. in [6] in their model of an all-optical transmission line. Basically, the transmission line is a repetition of identical Normalised Sections (NS). An NS applies hybrid compensation technique since it was concluded as the most optimum dispersion management technique to extend the all-optical reach of a transparent network.

Figure 1 illustrates the transmission line model which employs a hybrid compensation technique. It is made up of eight NS where each NS consists of SMF (Single Mode Fibre), two DCF (Dispersion Compensating Fibre) and two EDFAs (Erbium Doped Fibre Amplifiers).The two DCF sections are installed for the purpose of compensating dispersion accumulated from the transmission fibre, SMF. In order to reduce non-linear effects, slight under-compensation is applied. The compensation is equally divided into two DCF sections located before and after the SMF. However, since dispersion per-span is now under-compensated, the dispersion threshold is likely to be violated by the accumulated RD. This is especially true for high bit-rate services due to the reduced dispersion tolerance. The issue becomes more problematic when the RD value varies with wavelength as a result of dispersion slope. Figure 2 illustrates the measured RD of the different wavelengths at the receiver. In this example, wavelength $1,2,7$ and 8 are received outside the dispersion tolerance range.

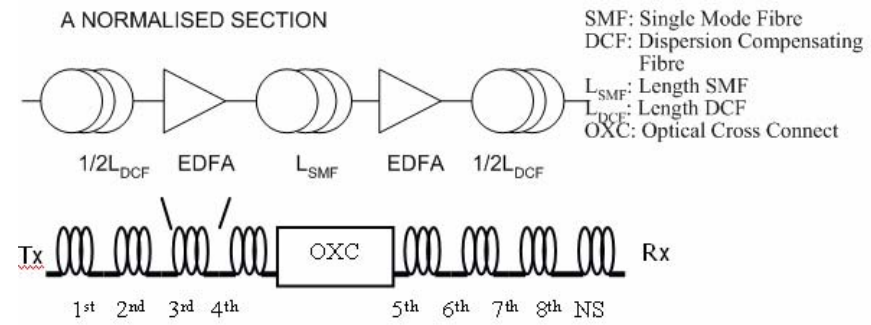

Figure 1. Transmission Line Based on NS Concept.

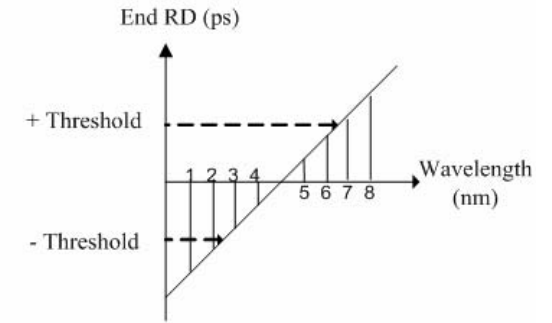

Figure 2. End RD vs. Received Wavelength.

In our routing and wavelength assignment approach, wavelengths are classified according to their $R D$ after one NS. Equation 1 shows RD of an $n^{\text {th }}$ wavelength which is equal to the total dispersion of transmission and compensating fibres after one NS. Our proposed ICBRA attempts to choose wavelengths which reside within the dispersion threshold range and whose end $\mathrm{RD}$ is closest to the dispersion threshold. In the case of a mixed bit- rate environment, several thresholds are pre-determined for different bit-rates. The dispersion thresholds, $C D_{\text {Threshold }}$ for $10 \mathrm{~Gb} / \mathrm{s}$ and $40 \mathrm{~Gb} / \mathrm{s}$ services used in this study are based on Equation 2 [5]. Here, the constant $\mathrm{k}$ is equal to 100000 while $B$ indicates bit-rate.

$$
\begin{aligned}
& R D_{\lambda n}=D_{\lambda n}(S M F) \times S M F \text { Length }+D_{\lambda n}(D C F) \times D C F \text { Length } \\
& \text { Where: } D_{\lambda n}=\text { Dispersion coefficient of the } \mathrm{n}^{\text {th }} \text { wavelength }(\mathrm{ps} / \mathrm{nm} \cdot \mathrm{km})=D_{\lambda R e f} \pm \Delta D \text {, } \\
& \left.D_{\lambda \text { Ref }}=\text { Dispersion coefficient of the reference wavelength (ps } / \mathrm{nm} . \mathrm{km}\right) \text {, } \\
& \Delta D=\text { Difference between } \mathrm{D}_{\lambda \text { Ref }} \text { and } \mathrm{D}_{\lambda \mathrm{n}}(\mathrm{ps} / \mathrm{nm} . \mathrm{km})=\Delta \lambda x S \text {, } \\
& \Delta \lambda=\text { Difference between the } \mathrm{n}^{\text {th }} \text { wavelength and reference wavelength }(\mathrm{nm}), \\
& S=\text { Dispersion slope }\left(\mathrm{ps} / \mathrm{nm}^{2} \mathrm{~km}\right) \text {, } \\
& C D_{\text {Threshold }}=\mathrm{k} / B^{2}
\end{aligned}
$$

\subsection{Optical to Signal Noise Ratio (OSNR)}

OSNR degradation in transparent optical networks is mainly contributed by the accumulation of Amplified Spontaneous Emission (ASE) noise generated by optical amplifiers. The generated ASE noise, $P_{\text {ase }}$ in general follows Equation 3 where $G$ is amplifier gain, $h$ is plank's constant, $F$ is linear noise figure, $\mathrm{v}$ is transmission frequency and $B o$ is optical bandwidth. The total ASE noise after $k$ stages is the accumulation of the noise from the previous stage $(k-1)$ and its own (Equation 4). Equation 5 depicts signal power after $k$ stages. $L_{f}(k)$ and $G_{E D F A}(k)$ are fibre loss and amplifier gain of the $k^{\text {th }}$ stage respectively. $M$ is the final stage before an egress node and $O S N R_{\text {system }}$ is equal to $M$ th's stage signal power divided by noise power (Refer to Equation 6). Relationship between received $O S N R\left(O S N R_{r c v d}\right), O S N R_{s y s t e m}$ and $O S N R_{i n}$ is described in Equation 7 where $O S N R_{\text {in }}$ is the input $O S N R$ at the transmitter. A connection will be rejected if its $O S N R_{r c v d}$ is lower than $O S N R_{\text {Threshold. The threshold }}$ values were obtained from physical layer modelling using Virtual Photonics Simulation Package, VPI ${ }^{\mathrm{TM}}$.

$$
\begin{aligned}
& P_{\text {ase }}=F \cdot h \cdot v \cdot(G-1) \cdot B o \\
& P_{\text {ase }}(k)=P_{\text {ase }}(k-1) \cdot L_{f}(k) \cdot G_{E D F A}(k)+P_{\text {ase }}(k) \\
& P_{\text {sig }}(k)=P_{\text {sig }}(k-1) \cdot L_{f}(k) \cdot G_{E D F A}(k)
\end{aligned}
$$




\section{DISPERSION OPTIMISED ICBRA AND WAVELENGTH ASSIGNMENT}

Equation 9 to 11 describes the link costs for $C D T, M F C$ and $D O I C$, respectively. $C D T$ only uses distance whereas $M F C^{l}$ [7] enhances $C D T$ with the addition of wavelength availability in its link cost calculation. Once the shortest distance path is found using djikstra's algorithm, first-fit wavelength assignment is implemented similarly to $C D T$ and $M F C$. Here, the first lowest numbered wavelength from a set of available wavelengths is chosen. The ascending order is from the lowest to highest $\pm R D$. Total accumulated $R D$ from a source to destination has to be within the threshold range (Equation 12).

The aim of link cost definition in DOIC is basically to increase the possibility of choosing a path with the lowest possible value of total accumulated $R D$. The denominator of Equation 11 is the sum of each available wavelength's weight. Consequently a path with wavelengths that have lower $R D$ values is likely to be chosen first as it gives lower cost. The constraint for DOIC's wavelength assignment is described in Equation 13. It selects the available wavelength which is closest to the threshold (not necessarily any first or the best). By doing this, the wavelength with lower $R D$ can be secured for future connections with tighter requirements. At the same time, the current connection can still experience an acceptable signal quality.

The notations and variables are defined as follows. $P$ is path, $d_{i, k}$ is distance between node $i$ and $k, R D(j)$ is $R D$ of $j$ th available wavelength after one NS and $S R D$ is the smallest value of $R D(j) . \lambda(\mathrm{j})_{\mathrm{i}, \mathrm{k}}$ indicates wavelength $\mathrm{j}$ between link $\mathrm{i}$ and $\mathrm{k}$ and equal to zero if it is unavailable and one if it is available.

$$
\begin{aligned}
& C D T\left(l_{i, k}\right)=d_{i, k} \quad \text { (9) } \quad \operatorname{MFC}\left(l_{i, k}\right)=\frac{d_{i, k}}{\sum_{j=1}^{N} \lambda(j)_{i, k}-1} \\
& \sum_{i, k \in P} d_{i, k} x|R D(j)| \leq C D_{\text {Threshold }} \\
& \operatorname{DOIC}\left(l_{i, k}\right)=\frac{d_{i, k} \times \sum_{j=1}^{N}|R D(j)|}{S R D \times \sum_{j=1}^{N} 1 /|R D(j)|} \\
& \sum_{i, k \in P} d_{i, k} x|R D(j)| \doteq \wedge \leq C D_{\text {Threshold }}
\end{aligned}
$$

\section{SIMULATION WORK}

A discrete time event simulator was constructed to investigate blocking probability of the three schemes: $C D T$, $M F C$ and DOIC. The reference topology is an Italian backbone network (Refer to Figure 3) which has 21 nodes and 36 bidirectional links. Average link distance is $180 \mathrm{~km}$ with the longest at $450 \mathrm{~km}$. Each link has the capacity of eight wavelengths, from $192.8 \mathrm{THz}$ to $193.5 \mathrm{THz}$. Residual dispersions $(R D)$ of the eight wavelengths after one NS are between $-18.80 \mathrm{ps} / \mathrm{nm}$ to $+14.02 \mathrm{ps} / \mathrm{nm}$. $C D_{\text {Threshold }}$ and $O S N R_{\text {Threshold }}$ for $10 \mathrm{~Gb} / \mathrm{s}$ (NRZ) and $40 \mathrm{~Gb} / \mathrm{s}(\mathrm{RZ})$ services are $\pm 1000 \mathrm{ps} / \mathrm{nm}, \pm 62.5 \mathrm{ps} / \mathrm{nm}, 11.747 \mathrm{~dB}$ and $14.8 \mathrm{~dB}$ respectively.

Each connection that arrives at time $t$ is identified by its source node $s$, destination node $d$, requested bandwidth $b$ and holding time $h$. Traffic arrival and departure rates are according to the Poisson distribution. Erlang load (Erlangs) is specified as arrival rate divided by departure rate. After path and wavelength have been assigned to a connection, the lightpath is confirmed to be within the OSNR and dispersion thresholds according to its bit-rate requirement. Successful connection requests will release the path after time $(t+h)$. Connections that cannot be routed without wavelength interchange and/or exceed either OSNR or dispersion thresholds are blocked. Blocking probability is defined as the ratio of total rejected calls divided by total demands.

Table 2. Parameters in SMF and DCF.

\begin{tabular}{|l|c|c|}
\hline Parameter & SMF & DCF \\
\hline Length $(\mathrm{km})$ & 50 & 9.44 \\
\hline $\begin{array}{l}\text { Attenuation } \\
(\mathrm{dB} / \mathrm{km})\end{array}$ & 0.2 & 0.6 \\
\hline $\begin{array}{l}\text { Dispersion } \\
(\mathrm{ps} / \mathrm{nm} . \mathrm{km})\end{array}$ & 17 & -90 \\
\hline $\begin{array}{l}\text { Dispersion Slope } \\
\left(\mathrm{ps} / \mathrm{nm}^{2} . \mathrm{km}\right)\end{array}$ & 0.08 & 0.21 \\
\hline
\end{tabular}

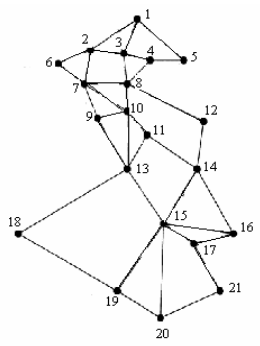

Figure 3. Italian Network.

Figure 4 shows blocking probability performance versus network load (Erlangs) for the three algorithms: $C D T$, $M F C$ and DOIC when requests are $40 \mathrm{~Gb} / \mathrm{s}$ (Figure $4 a$ ) and mixed 10/40 Gb/s (Figure $4 b$ ). DOIC has the best performance for blocking probability, followed by $M F C$ and $C D T$. Having the additional free wavelength metric in $M F C$ contributes little to the improvement of $C D T$, which is based on distance alone. Consider the case where the network operates at 5\% blocking probability. DOIC in scenario A $(40 \mathrm{~Gb} / \mathrm{s})$ is able to serve 6 times more

\footnotetext{
${ }^{1} M F C$ in this paper is the modified version of the future-cost algorithm which also includes distance in this paper.
} 
load than the other schemes, which is equivalent to an extra $200 \mathrm{~Gb} / \mathrm{s}$ to the overall network capacity. The improvement is more obvious in the case of the mixed bit-rate scenario $(10 / 40 \mathrm{~Gb} / \mathrm{s})$ for all schemes (Figure $4 b)$. In this case, both $C D T$ and $M F C$ can provision loads of around 4 Erlangs. This indicates a maximum overall network capacity of $100 \mathrm{~Gb} / \mathrm{s}$ since the generated traffic consists of equal amounts of $10 \mathrm{~Gb} / \mathrm{s}$ and $40 \mathrm{~Gb} / \mathrm{s}$ services. In comparison, DOIC supports traffic loads of around 24 Erlangs for the same blocking probability $(5 \%)$ which equates to $600 \mathrm{~Gb} / \mathrm{s}$ : an additional $500 \mathrm{~Gb} / \mathrm{s}$ to the overall network capacity compared with $C D T$ and MFC. DOIC works more efficiently in the mixed bit-rate scenario since it considers the possibility of future connections with longer distance or higher bit-rates which require wavelengths with lower $R D$. It does this by ensuring that all $10 \mathrm{~Gb} / \mathrm{s}$ connections are assigned the wavelengths with the highest $R D$ (but within the $10 \mathrm{~Gb} / \mathrm{s}$ $R D$ and OSNR thresholds) to preserve the number of low residual dispersion wavelengths for the more demanding $40 \mathrm{~Gb} / \mathrm{s}$ connection requests.

Blocking Probability Vs Erlang Load (40Gbps)

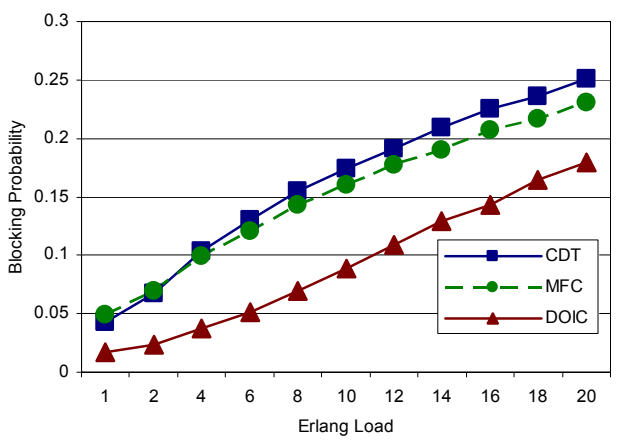

Figure 4 (a) Blocking Probability vs Erlangs $(40 \mathrm{~Gb} / \mathrm{s})$.
Blocking Probability Vs Erlang Load (10/40Gbps)

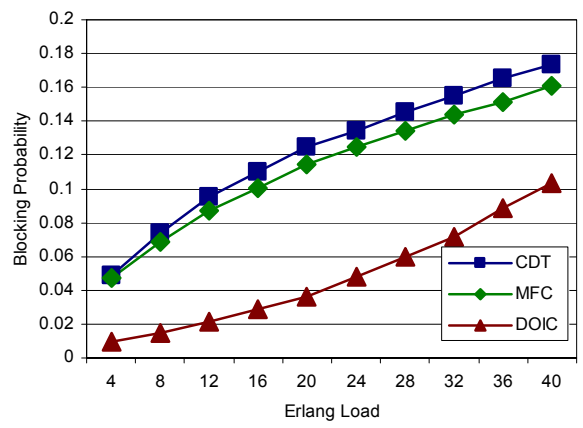

Figure 4. (b) Blocking Probability vs Erlangs $(10 / 40 \mathrm{~Gb} / \mathrm{s})$.

\section{CONCLUSIONS}

This paper demonstrated that the inclusion of dispersion metrics to both the routing and wavelength assignment sub-problems can significantly reduce the connection blocking probability when compared with algorithms that do not consider dispersion as a metric. The newly proposed algorithm, DOIC, was demonstrated to perform even better in a mixed bit-rate scenario $(10 / 40 \mathrm{~Gb} / \mathrm{s})$ where service requirements are differentiated based on bit-rate. By virtue of assigning a wavelength with the maximum tolerable residual dispersion (RD) value for lower bitrate services, DOIC maximizes the number of lower RD wavelengths for the $40 \mathrm{~Gb} / \mathrm{s}$ services.

Future work will involve the inclusion of other impairments (e.g. PMD and non-linear penalties) and address heterogeneous networks with different technologies, mixed fibre types and different dispersion compensation techniques.

\section{REFERENCES}

[1] J. Strand, A.L. Chiu and R. Tkach, "Issues for Routing in The Optical Layer," IEEE Communications Magazine, February 2001.

[2] M. Ali and D. Penninckx, "Provisioning Methods for Bit Rate Differentiated Service in Hybrid Optical Networks," Photonics Network Communication, pp. 59-76, 2004.

[3] Y. Huang, J.P. Heritage, and B, Mukherjee, "Connection provisioning with transmission impairment consideration in optical WDM networks with high-speed channels," Journal of Lightwave Technology, vol. 23, no. 3, pp. 982-993, March 2005.

[4] I. Tomkos, et al., "Performance Engineering of Metropolitan Area Networks Through Impairment Constraint Routing," IEEE Optical Communications, August 2004.

[5] L.G. Nielsen, "Dispersion Compensating, Techniques and Systems Requirements," European Conference on Optical Communication, ECOC, September 2003.

[6] N. Hanik, et al., "Extension of All-Optical Network Transparent Domains Based on Normalized Transmission Sections," Journal of Lightwave Technology, vol.22, no. 6, pp. 1439-1453, 2004.

[7] C. Assi, A. Shami, M.A. Ali, R. Kurtz, and D. Guo, "Optical networking and realtime provisioning: an integrated vision for the next-generation Internet," IEEE Network, July/August 2001. 